\title{
Poly(lactic acid)/thermoplastic starch sheets: effect of adipate esters on the morphological, mechanical and barrier properties
}

\author{
Marianne Ayumi Shirai ${ }^{1,2 *}$, Juliana Bonametti Olivato', Ivo Mottin Demiate ${ }^{3}$, Carmen Maria Olivera Müller ${ }^{4}$, \\ Maria Victória Eiras Grossmann ${ }^{1}$ and Fabio Yamashita ${ }^{1}$
}

\author{
${ }^{1}$ Department of Food Science and Technology, Universidade Estadual de Londrina - UEL, \\ Londrina, PR, Brazil \\ ${ }^{2}$ Department of Food Technology, Universidade Tecnológica Federal do Paraná - UTFPR, \\ Campus Londrina, Londrina, PR, Brazil \\ ${ }^{3}$ Department of Food Engineering, Universidade Estadual de Ponta Grossa - UEPG, \\ Ponta Grossa, PR, Brazil \\ ${ }^{4}$ Department of Food Science and Technology, Universidade Federal de Santa Catarina - UFSC, \\ Florianópolis, SC, Brazil \\ *marianneshirai@utfpr.edu.br
}

\begin{abstract}
Blends of poly(lactic acid) (PLA) and thermoplastic starch (TPS) plasticized with adipate esters (diisodecyl adipate and diethyl adipate) having different molecular weight were used to produce sheets. The calendering-extrusion process at a pilot scale was used, and the mechanical, barrier, and morphological characterization of the obtained materials were performed. The increase in the TPS content affected the mechanical properties of the sheets by increasing the elongation and decreasing the rigidity. TPS conferred a more hydrophilic character to the sheets, as observed from the water vapor permeability results. The sheets plasticized with diisodecyl adipate (DIA), having a higher molecular weight, had better mechanical and barrier properties than diethyl adipate (DEA) plasticized sheets, indicating that DIA was more effective as plasticizer. Micrographs obtained by confocal laser microscopy and scanning electron microscopy showed different morphologies when different proportions of PLA and TPS were used (dispersed or co-continuous structures), which were strongly associated with the mechanical and barrier properties.
\end{abstract}

Keywords: biodegradable material, polymeric blend, plasticizer, mechanical properties.

\section{Introduction}

The interest in producing plastic materials from natural resources is considerably increasing as the need for the reduction of the amount of plastic waste in the environment becomes urgent ${ }^{[1]}$. Due to its biodegradability, low cost, and worldwide availability, starch in the form of thermoplastic starch (TPS) has been extensively studied as a main component in the production of biodegradable materials. TPS is usually obtained by destroying the crystalline structure of native starch through an extrusion process in the presence of plasticizers, such as glycerol ${ }^{[2-4]}$.

Unfortunately, TPS-based materials are hygroscopic and have limited performance. To overcome this deficiency, the TPS must be blended with another biodegradable polymer to produce materials for packaging and industrial applications ${ }^{[5,6]}$. In this context, the blend of TPS with poly (lactic acid) (PLA) is promising because, in addition to being compostable, PLA is produced from a renewable resource. PLA has received much attention as the most innovative alternative to conventional petroleum-based polymers and has been intensively studied due to its environmentally friendly characteristics such as biocompatibility, sustainability, and potentially useful physical and mechanical properties.
The addition of TPS into a PLA matrix can also decrease the material cost and increase its biodegradation rate ${ }^{[5,7,8]}$.

Blending native starch with PLA could increase its rigidity but simultaneously greatly reduce its elongation at break and impact strength ${ }^{[9]}$. Many factors are believed to cause the deterioration in mechanical properties of PLA/starch blends. First, PLA has an inherent brittleness as evidenced by its relatively low tensile strain at break, and toughness ${ }^{[10,11]}$. Another explanation is linked to the inherent incompatibility between the hydrophilic starch and the hydrophobic PLA that affects the interfacial adhesion ${ }^{[5,7,12-15]}$

It is well known that the mechanical and barrier properties of polymer blends are strongly related to their morphology. The relationship of the mechanical and water vapor barrier properties to the morphology of PLA and starch blends has been studied by other authors ${ }^{[16-18]}$. Blends of TPS and PLA can result in a wide variety of morphologies from a dispersed starch/PLA matrix, a co-continuous starch/PLA structure, to inverted phase morphologies, in which the starch is the continuous phase ${ }^{[19]}$.

Addition of an adequate plasticizer and compatibilizer can improve the processability and flexibility of PLA, enabling the blending with starch to produce sheets with adequate 
mechanical properties. Another way to enhance the interfacial affinity is the addition of previously gelatinized starch to the blend. The disintegrated starch granules overcome the strong interactions between the starch molecules and, in the presence of water and other plasticizers, leads to good dispersion $^{[20,21]}$.

In the previous work adipate esters, compared with citrate esters, improved the mechanical properties of TPS/PLA films produced by blown extrusion ${ }^{[22]}$ and TPS/PLA sheets obtained by calendering extrusion, ${ }^{[23]}$ reducing the elastic modulus and the tensile strength and increasing the elongation at rupture. Adipate esters were also studied by other authors ${ }^{[24,25]}$ to enable the production of flexible PLA films.

The current study focuses on the production of sheets with different proportions of TPS and PLA and plasticized with two different adipate esters. The morphologies of these sheets are correlated with the mechanical and barrier properties.

\section{Materials and Methods}

\subsection{Materials}

For the production of biodegradable sheets, PLA Ingeo 4043D (Natureworks LLC, Cargill, Blair, Nebraska, USA) with average molecular weight of $200 \mathrm{kDa}$ and native cassava starch (Indemil, Paranavaí, Brazil) were used. Commercial glycerol (Dinamica, Diadema, Brazil) was used as a plasticizer for the starch. Diisodecyl adipate $(426.67 \mathrm{~g} / \mathrm{mol})$ and diethyl adipate $(202.25 \mathrm{~g} / \mathrm{mol})$ (Sigma Aldrich, Steinheim, Germany) were used as plasticizing agents for the PLA.

\subsection{PLA/TPS Sheet Production}

Biodegradable sheets with different proportions of PLA and TPS (60/40, 50/50, 40/60, 30/70, 20/80 and 10/90, w/w) were produced, and the concentration of glycerol was $33 \mathrm{~g} / 100 \mathrm{~g}$ starch. Two different adipate esters, diisodecyl adipate (DIA) and diethyl adipate (DEA) were used, and the concentration employed was $10 \mathrm{~g}$ adipate ester/100 $\mathrm{g}$ PLA.

All of the components (PLA, starch, glycerol, and adipate ester) were manually mixed and processed using a pilot twin-screw extruder (BGM, D-20 model, Brazil) with a screw diameter of $20 \mathrm{~mm}(\mathrm{~L} / \mathrm{D}=35)$. The screw speed was $100 \mathrm{rpm}$, the feed speed was $30 \mathrm{rpm}$, and a temperature profile from entrance to exit of $100 / 180 / 180 / 180 / 180^{\circ} \mathrm{C}$ was used.

The extruded cylindrical profiles obtained were pelletized and extruded again in the same twin-screw extruder coupled with a calender (AX-Plasticos, Brazil) for sheet production. The temperature profile from entrance to exit was $100 / 170 / 170 / 170 / 175^{\circ} \mathrm{C}$, the distance between the calender rolls was $0.8 \mathrm{~mm}$, and the roll speed was adjusted for each formulation to maintain a continuous process.

\subsection{Thickness}

The film thicknesses were measured using a digital micrometer (Starrett, Brazil) at ten different locations on the films.

\subsection{Mechanical properties}

Tensile tests were performed using a texture analyzer (Stable Micro Systems, TA XTplus, England) based on the ASTM D882-02 standard ${ }^{[26]}$. The specimens were previously conditioned at $23 \pm 2{ }^{\circ} \mathrm{C}$ and $53 \pm 2 \%$ for 48 hours, and the tensile strength $(\mathrm{MPa})$, elongation at break (\%), and Young's modulus (MPa) were measured. The tests were repeated ten times for each formulation.

\subsection{Water vapor permeability}

The water vapor permeability (WVP) of the sheets was determined gravimetrically, according to the ASTM E96-00 standard ${ }^{[27]}$. The sheets were previously stored at $23 \pm 2{ }^{\circ} \mathrm{C}$ and $53 \pm 2 \%$ for 48 hours and then fixed in the 60 -mm-diameter cylindrical aluminum cells. The interior of the cell was filled with calcium chloride $(0 \% \mathrm{RH})$, and the device was stored at $25^{\circ} \mathrm{C}$ in a desiccator containing a saturated sodium chloride solution $(75 \% \mathrm{RH})$.

The samples were weighed in semi-analytical balance (Marte, Brazil) every $12 \mathrm{~h}$ during the 5 days of testing. The mass gain $(\mathrm{m})$ of the cell was plotted as a function of the time $(\mathrm{t})$. The slope of the line was calculated using linear regression $\left(\mathrm{R}^{2}>0.99\right)$, and the water vapor permeation ratio (WVPR) was calculated using Equation 1:

$$
W V P R=(m / t) x(1 / A)
$$

where $m / t$ is the angular coefficient of the curve and $A$ is the sample permeation area $\left(\mathrm{m}^{2}\right)$. The WVP $(\mathrm{g} / \mathrm{m}$.day.Pa) was calculated as follows (Equation 2):

$$
W V P=(W V P R x e) / p(R H 1-R H 2)
$$

where $\mathrm{e}$ is the mean sample thickness $(\mathrm{m}), p$ is the water vapor saturation pressure at the assay temperature $(\mathrm{Pa})$, $R H_{1}$ is the relative humidity of the desiccator and $R H_{2}$ is the relative humidity in the interior of the permeation cell. The test was conducted in duplicate.

\subsection{Morphological characterization}

The sheet fracture morphology was evaluated using scanning electron microscopy (Philips, FEI Quanta 200 model, Japan). The sheets were fractured after immersion in liquid nitrogen and gold coated using a sputter coater (Bal-Tec, SCD-050 model, Balzers, Liechtenstein). All of the samples were examined using an accelerating voltage of $20 \mathrm{kV}$ at a magnification of $400 x$.

A confocal laser scanning microscope (Olympus LEXT, OLS400 model, Germany) was used to obtain surface images of the sheets.

\subsection{Statistical analysis}

The obtained results were evaluated using the analysis of variance (ANOVA), and the treatment means were compared using Tukey's test at a $5 \%$ significance level $(\mathrm{p}<0.05)$ with Statistica 7.0 software (STATSOFT, USA). 


\section{Results and Discussion}

\subsection{Thickness}

It was not possible to produce sheets with PLA/TPS proportions of $20 / 80$ and $10 / 90$, because the extruded materials were too stiff to be processed through the calender rolls. The other formulations had good processability, and the sheets showed slightly rough surfaces. As the starch amount increased, the color became more yellowish.

The thickness of the PLA/TPS sheets with adipate esters added ranged from 431 to $815 \mu \mathrm{m}$ (Table 1). Considering the effect of TPS addition, the increase in its concentration conferred thicker sheets for PLA plasticized with DIA. In the same way, evaluating the effect of the plasticizer type, the sheets with DIA were less thick than those with DEA for the same TPS/PLA compositions. This result could be related to the DIA plasticizing effect that enhanced the flexibility and allowed increased stretching of the sheets by the calender rolls. During the calendering extrusion process, the sheet thickness was controlled by the distance between the rolls, the speed of the rolls, and the stretching capacity of the formulation, as observed in our previous study ${ }^{[23]}$.

\subsection{Morphological characterization}

The fracture micrographs of the PLA/TPS sheets examined using SEM at 400x magnification are presented in Figure 1. For the 60/40 and 50/50 PLA/TPS sheets with DEA and DIA, starch granules with different sizes were dispersed in the PLA matrix. When the concentration was reduced to 30/70 PLA/TPS, PLA was present as a dispersed phase in the TPS matrix, evidencing a phase inversion point. According to the literature, ${ }^{[28]}$ the co-continuity occurs at the phase inversion point and when both polymers are approximately in equal concentration. Furthermore, in the case of starch/PLA blends, co-continuity occurs for a low proportion of starch because the starch phase is less viscous and has a high interfacial tension. Generally, for up to $40 / 60 \mathrm{PLA} / \mathrm{TPS}$, a dispersed starch phase in the matrix morphology was observed. Below this proportion of PLA, a co-continuous morphology was obtained. A similar behavior was also observed in blends of PLA and starch with varied amylose contents ${ }^{[16]}$ and in blends of PLA and chemically modified corn $\operatorname{starch}^{[18]}$.

In the sheets with higher proportions of PLA, some spaces between the PLA and TPS phases were evident, showing the interface between the polymers. This result could be associated with poor interaction and incompatibility

Table 1. Thickness of PLA/TPS sheets plasticized with adipate ester.

\begin{tabular}{ccc}
\hline \multirow{2}{*}{ PLA/TPS } & \multicolumn{2}{c}{ Thickness $(\boldsymbol{\mu m})$} \\
\cline { 2 - 3 } & DEA & DIA \\
\hline $60 / 40$ & $764 \pm 2^{\mathrm{b}}$ & $538 \pm 7^{\mathrm{d}}$ \\
$50 / 50$ & $749 \pm 8^{\mathrm{b}}$ & $431 \pm 69^{\mathrm{e}}$ \\
$40 / 60$ & $753 \pm 9^{\mathrm{b}}$ & $619 \pm 5^{\mathrm{c}}$ \\
$30 / 70$ & $815 \pm 21^{\mathrm{a}}$ & $736 \pm 31^{\mathrm{b}}$ \\
\hline
\end{tabular}

Different letters represent significant differences $(p \leq 0.05)$ between the means obtained by Tukey's test. PLA = poly (lactic acid); TPS $=$ thermoplastic starch; DEA = diethyl adipate; DIA = diisodecyl adipate between the starch and PLA because of the difference in hydrophobicity, as observed in other reports ${ }^{[7,12-14,17,18,29-31]}$.

Confocal laser microscopy (CLM) is usually employed to study the surface morphology of polymeric films and sheets and confer information about the surface topography and heterogeneity. In this study, CLM was used to analyze the surface properties of the PLA/TPS sheets plasticized with DEA or DIA, and the obtained images are shown in Figure 2. Sheets with a higher proportion of PLA had increase surface roughness. This result can be attributed to the starch granules dispersed in the PLA matrix, as observed in the fractured SEM images. The roughness decreased as the PLA concentration decreased due phase inversion, in which TPS was the continuous phase. CLM was also used to evaluate the surface roughness of the starch films treated by plasma ${ }^{[1]}$ and to identify the blend compositions that correspond to the beginning of partial continuity until total continuity of the poly(butylene succinate-co-adipate) (PBSA) and TPS phases ${ }^{[32]}$.

\subsection{Mechanical properties}

The Figure 3 shows the mechanical properties in terms of the tensile strength $(\mathrm{MPa})$, elongation at rupture $(\%)$ and Young's modulus (MPa) of the PLA/TPS sheets plasticized with adipate esters.

As the TPS concentration increased, the tensile strength and Young's modulus of all of the sheets significantly decreases. For the elongation at break, only the sheets plasticized with DEA exhibited a significant increase when the TPS concentration increased. The sheets plasticized with DIA maintained this property for all of the tested TPS concentrations. For the blends with PLA as a continuous phase, DIA interacted better with it and aided in the induced crystallization due chain alignment during the tensile test. This result caused tensile energy diffusion and led to plastic deformation of the PLA matrix. The statistically equal mechanical properties for the 30/70 PLA/TPS sheets support these results. Different results were observed in our previous study ${ }^{[23]}$ in which DEA with lower molecular weight promoted greater values of elongation of break than DIA. Xiong et al. ${ }^{[21]}$ and Xiong et al. ${ }^{[33]}$ evaluated the effects of plant oils such as Tung oil anhydride and epoxidized soybean oil as plasticizers in PLA/TPS blends containing approximately $60 \%$ of PLA and reported a decrease in the tensile strength and an increase in the elongation at break of the blends.

Comparing the effects of the adipate esters as plasticizers, DIA promoted higher values of the elongation at break and the Young's modulus; however, the same tensile strength values were observed for the two plasticizers. It is possible to conclude that adipate esters with higher molecular weight promoted materials with greater elongation, as observed by other authors ${ }^{[24]}$ that used polyadipate as a plasticizer for PLA films.

As observed in the SEM and CLM images, the starch granules dispersed in the PLA matrix act as defects and lead to serious stress concentration, which the material easier to fracture ${ }^{[21]}$. The presence of spaces between the starch and PLA also impaired the load transfer under stress. Therefore, the tensile strength and elongation at break of 


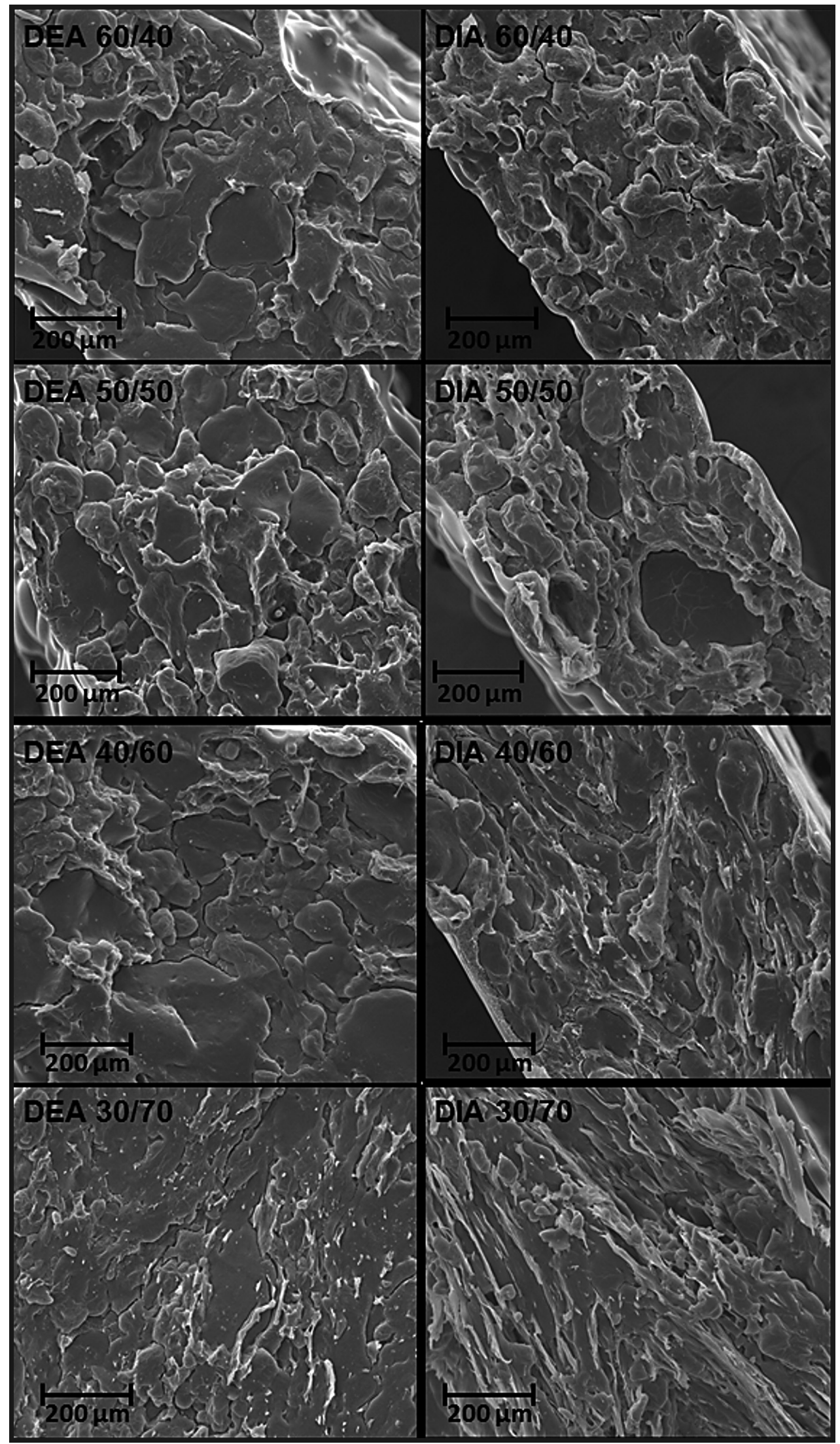

Figure 1. SEM (400 X) of PLA/TPS sheets plasticized with adipate esters. 


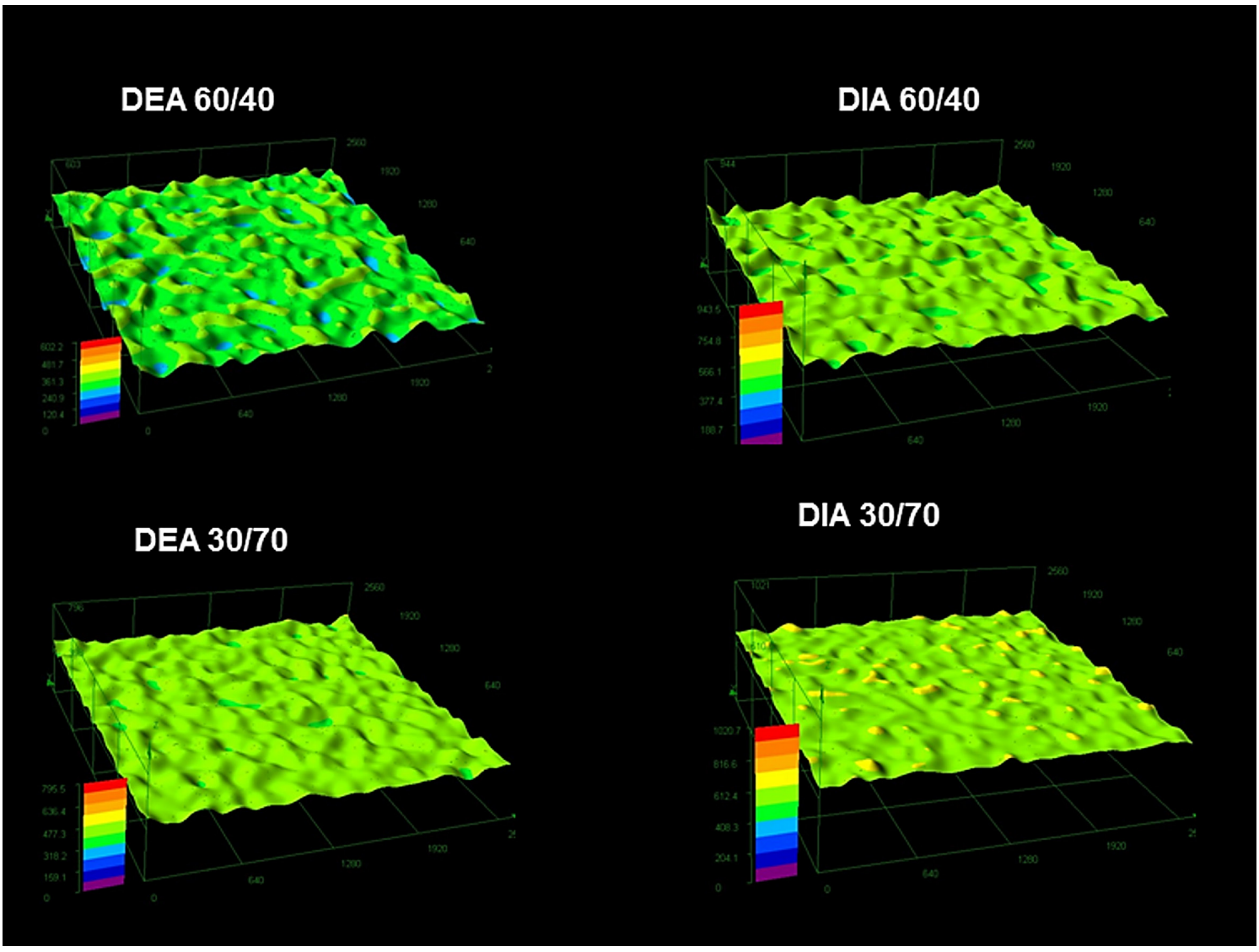

Figure 2. Confocal microscopy images of PLA/TPS sheets plasticized with adipate esters.

the materials are directly linked to interfacial adhesion between the polymers used in the blends. Similar results for PLA/starch blends plasticized with acetyl triethyl citrate were reported ${ }^{[12]}$.

The mechanical properties of the 30/70 PLA/TPS samples were similar for both plasticizers, suggesting that in the case of a dispersed phase (PLA) surrounded by a continuous phase (TPS), the mechanical properties of these immiscible blends depend on those of the continuous phase because it absorbs the stress and energy when the material is under load ${ }^{[28]}$. When percolation occurs, a part or total of one phase forms a continuous structure that permeates the entire sample and eventually dominates the properties of the blend. In our case, as the TPS levels increased, the interface properties improved, as observed by MEV. As a result, the tensile strength of the sheets was expected to increase; however, this result did not occur because the TPS has a lower tensile strength and Young's modulus than the PLA.

Comparing the obtained results with other results reported in the literature, lower values of the tensile strength, Young's modulus and elongation at break were obtained in PLA/TPS (30 g PLA / $100 \mathrm{~g}$ TPS) films produced by extrusion and thermopressing ${ }^{[29,30]}$ In this case, because TPS was the continuous phase, it was responsible for the mechanical properties of the films, resulting in more fragile materials. PLA/TPS films (20\% TPS) with increased resistance were produced by Teixeira et al. ${ }^{[34]}$ due the addition of cassava bagasse.

\subsection{Water vapor permeability (WVP)}

The WVP of the PLA/TPS sheets with added adipate esters ranged from $2.94 \times 10^{-6}$ to $6.98 \times 10^{-6} \mathrm{~g}$ day $^{-1} \mathrm{~m}^{-1} \mathrm{~Pa}^{-1}$, as shown in Figure 4. The values obtained are lower than those observed for cassava starch films ${ }^{[35,36]}$ and PLA/TPS films ${ }^{[29]}$ and greater than PLA films with synthetic phenolic antioxidants added ${ }^{[37]}$. The presence of PLA promoted a hydrophobic character of the material and was responsible for decreasing the WVP because the material permeability is strongly influenced by the hydrophobic or hydrophilic nature of its components.

The increase in the TPS concentration (from 60/40 to 30/70) elevated the WVP because of the hydrophilic character of the starch. Furthermore, at high starch contents, water could easily saturate the surface of the blend, penetrate into these voids and be quickly absorbed by the starch, resulting in higher water permeation ${ }^{[16]}$.

Comparing the type of adipate ester, the sheets with DIA had lower WVP than sheets with DEA, mostly in the materials with a higher proportion of PLA. To support the discussion of the results, the plasticizing capacity of the adipate esters was calculated by dividing the molecular weight by the hydrogen bond capacity of each component, resulting 

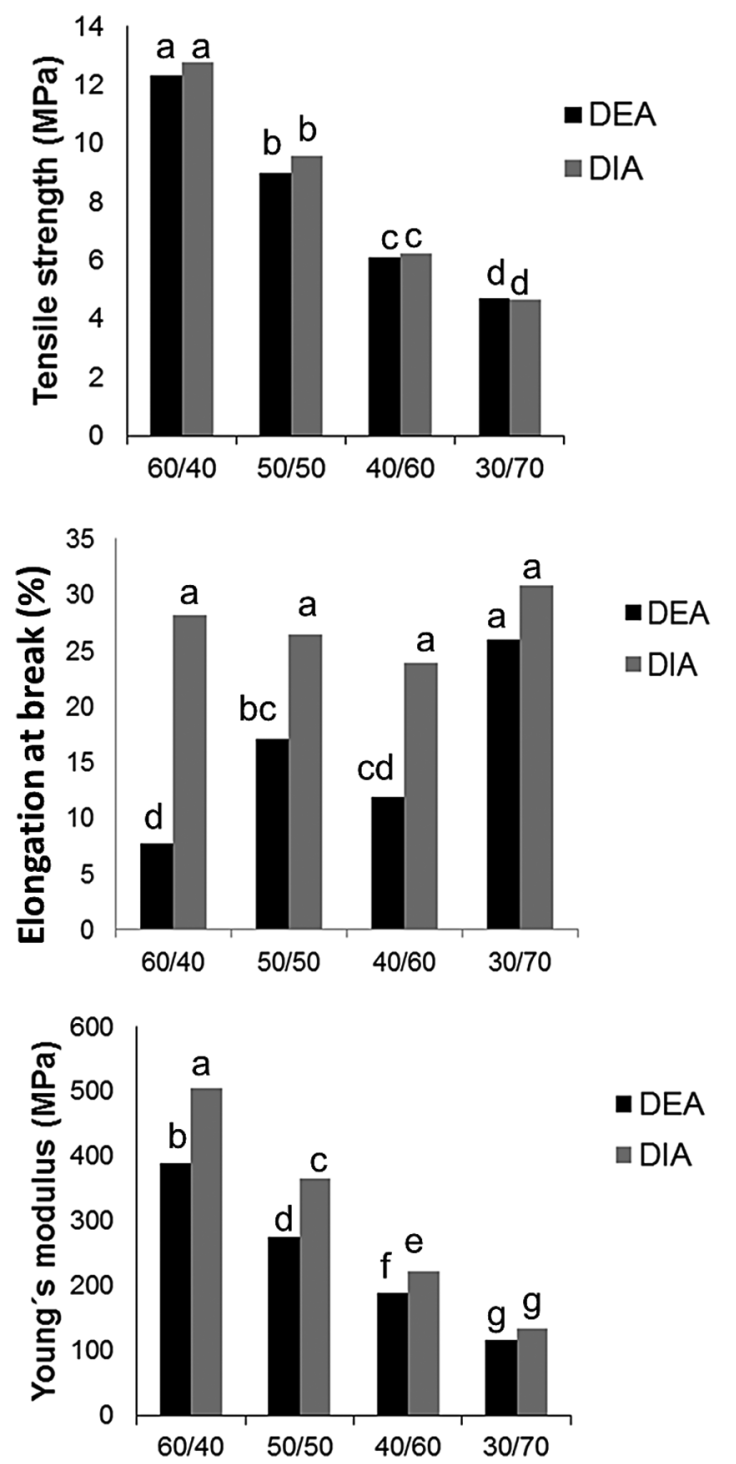

Figure 3. Mechanical properties of PLA/TPS sheets plasticized with DEA and DIA. Different letters represent significant difference $(\mathrm{p} \leq 0.05)$ between the means obtained by Tukey's test.

in $9.9 \times 10^{3}$ and $4.7 \times 10^{3}$ for DEA and DIA, respectively. DEA presented a higher value and consequently a better plasticizing capacity that increased the intermolecular distance between the chains and the free volume, facilitating the penetration of water molecules into the polymer matrix. This fact and the longer chains of the DIA explain the lower WVP values of the DIA-added PLA/TPS sheets. Similar results for PLA/TPS sheets plasticized with DEA were observed in our previous study ${ }^{[23]}$.

Finally, the final WVP is a balance between the hydrophilic and hydrophobic character of the blend components and the interface properties. The greater the tension at the interface (less compatible blends), the greater the spaces between the phases, which facilitates water diffusion.

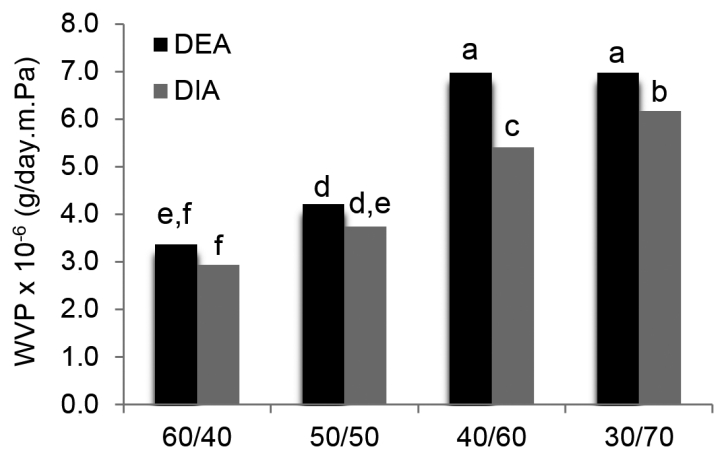

Figure 4. Water vapor permeability of PLA/TPS sheets plasticized with DEA and DIA. Different letters represent significant difference $(p \leq 0.05)$ between the means obtained by Tukey's test.

\section{Conclusion}

Calendering extrusion is a feasible way to produce PLA/TPS sheets at a pilot scale with great potential to be used in packaging production. Different proportions of PLA and TPS in the blends confer sheets with modified morphological structures (dispersed or co-continuous structures), which significantly affect the mechanical and barrier properties.

Adipate esters are excellent plasticizers for PLA in PLA/TPS sheets. DIA, because of its higher molecular weight, was the better plasticizer for PLA conferring sheets with higher elongation at break, tensile strength, Young's modulus, as well as reduced WPV.

\section{Acknowledgements}

The authors would like to thank CAPES, CNPq and Fundação Araucaria for their financial support and research grants and the Microscopy Laboratory of UEL for the use of their scanning electron microscope.

\section{References}

1. Bastos, D. C., Santos, A. E. F., Silva, M. L. V. J., \& Simão, R. A. (2009). Hydrophobic corn starch thermoplastic films produced by plasma treatment. Ultramicroscopy, 109(8), 1089-1093. http://dx.doi.org/10.1016/j.ultramic.2009.03.031. PMid:19345017.

2. Avérous, L., Fringant, C., \& Moro, L. (2001). Plasticized starch-cellulose interaction in polysaccharide composites. Polymer, 42(15), 6565-6572. http://dx.doi.org/10.1016/S00323861(01)00125-2.

3. Liu, H., Xie, F., Yu, L., Chen, L., \& Li, L. (2009). Thermal processing of starch-based polymers. Progress in Polymer Science, 34(12), 1348-1368. http://dx.doi.org/10.1016/j. progpolymsci.2009.07.001.

4. Zullo, R., \& Iannace, S. (2009). The effects of different starch sources and plasticizers on film blowing of thermoplastic starch: Correlation among process, elongational properties and macromolecular structure. Carbohydrate Polymers, 77(2), 376-383. http://dx.doi.org/10.1016/j.carbpol.2009.01.007.

5. Li, H., \& Huneault, M. A. (2011). Comparison of sorbitol and glycerol as plasticizers for thermoplastic starch in TPS/PLA blends. Journal of Applied Polymer Science, 119(4), 2439-2448. http://dx.doi.org/10.1002/app.32956. 
6. Abdillahi, H., Chabrat, E., Rouilly, A., \& Rigal, L. (2013). Influence of citric acid on thermoplastic wheat flour / poly(lactic acid) blends. II. Barrier properties and water vapour sorption isotherms. Industrial Crops and Products, 50, 104-111. http:// dx.doi.org/10.1016/j.indcrop.2013.06.028.

7. Martin, O., \& Averous, L. (2001). Poly(lactic acid): plasticization and properties of biodegradable multiphase systems. Polymer, 42(14), 6209-6219. http://dx.doi.org/10.1016/S00323861(01)00086-6.

8. Babu, R. P., O’Connor, K., \& Seeram, R. (2013). Current progress on bio-based polymers and their future trends. Progress in Biomaterials, 2(8), 1-16. http://dx.doi.org/10.1186/21940517-2-8.

9. Jacobsen, S., \& Fritz, H. G. (1999). Plasticizing polylactide: The effect of different plasticizers on the mechanical properties. Polymer Engineering and Science, 39(7), 1303-1310. http:// dx.doi.org/10.1002/pen.11517.

10. Bhardwaj, R., \& Mohanty, A. K. (2007). Advances in the properties of polylactides based materials: a review. Journal of Biobased Materials Bioenergy, 1(2), 191-209. http://dx.doi. org/10.1166/jbmb.2007.023.

11. Anderson, K. S., Schreck, K. M., \& Hillmyer, M. (2008). Toughening polylactide. Polymer Reviews, 48(1), 85-108. http://dx.doi.org/10.1080/15583720701834216.

12. Zhang, J. F., \& Sun, X. Z. (2004). Mechanical properties of poly(lactic acid)/starch composites compatibilized by maleic anhydride. Biomacromolecules, 5(4), 1446-1451. http://dx.doi. org/10.1021/bm0400022. PMid:15244463.

13. Wang, N., Yu, J., Chang, P. R., \& Ma, X. (2008). Influence of formamide and water on the properties of thermoplastic starch/poly(lactic acid) blends. Carbohydrate Polymers, 71(1), 109-118. http://dx.doi.org/10.1016/j.carbpol.2007.05.025.

14. Kozlowski, M., Masirek, R., Piorkowska, M., \& GazickiLipman, M. (2007). Biodegradable blends of poly(L-lactide) and starch. Journal of Applied Polymer Science, 105(1), 269277. http://dx.doi.org/10.1002/app.26088.

15. Lim, L. T., Auras, R., \& Rubino, M. (2008). Processing technologies for poly(lactic acid). Progress in Polymer Science, 33(8), 820852. http://dx.doi.org/10.1016/j.progpolymsci.2008.05.004.

16. Ke, T., Sun, S. X., \& Seib, P. (2003). Blending of Poly(lactic acid) and starches containing varying amylose content. Journal of Applied Polymer Science, 89(13), 3639-3646. http://dx.doi. org/10.1002/app.12617.

17. Jang, W. Y., Shin, B. Y., Lee, T. J., \& Narayan, R. (2007). Thermal properties and morphology of biodegradable PLA/starch compatibilized blends. Journal of Industrial and Engineering Chemistry, 13(3), 457-464. Retrieved in 22 February 2015, from http://infosys.korea.ac.kr/research/tech/periodicals/view. php?seq $=581012$

18. Shin, B. Y., Jang, S. H., \& Kim, B. S. (2011). Thermal, morphological, and mechanical properties of biobased and biodegradable blends of poly(lactic acid) and chemically modified thermoplastic starch. Polymer Engineering and Science, 51(5), 826-834. http://dx.doi.org/10.1002/pen.21896.

19. Huneault, M. A., \& Li, H. (2007). Morphology and properties of compatibilized polylactide/thermoplastic starch blends. Polymer, 48(1), 270-280. http://dx.doi.org/10.1016/j.polymer.2006.11.023.

20. Park, J. W., Im, S. S., Kim, S. H., \& Kim, Y. H. (2000). Biodegradable polymer blends of poly(L-lactic acid) and gelatinized starch. Polymer Engineering and Science, 40(12), 2539-2550. http://dx.doi.org/10.1002/pen.11384.

21. Xiong, Z., Yang, Y., Feng, J., Zhang, X., Zhang, C., Tang, Z., \& Zhu, J. (2013). Preparation and characterization of poly(lactic acid)/ starch composites toughened with epoxidized soybean oil. Carbohydrate Polymers, 92(1), 810-816. http://dx.doi. org/10.1016/j.carbpol.2012.09.007. PMid:23218370.
22. Shirai, M. A., Grossmann, M. V. E., Mali, S., Yamashita, F., Garcia, P. S., \& Müller, C. M. O. (2013). Development of biodegradable flexible films of starch and poly(lactic acid) plasticizes with adipate or citrate esters. Carbohydrate Polymers, 92(1), 19-22. http://dx.doi.org/10.1016/j.carbpol.2012.09.038. PMid:23218260.

23. Shirai, M. A., Müller, C. M. O., Grossmann, M. V. E., \& Yamashita, F. (2015). Adipate and citrate esters as plasticizers for poly(lactic acid) / thermoplastic starch sheets. Journal of Polymer and Environment, 23(1), 54-61. http://dx.doi. org/10.1007/s10924-014-0680-9.

24. Martino, V. P., Ruseckaite, R. A., Jiménez, A., \& Averous, L. (2010). Correlation between composition, structure and properties of poly(lactic acid)/polyadipate-based nano-biocomposites. Macromolecular Materials and Engineering, 295(6), 551-558. http://dx.doi.org/10.1002/mame.200900351.

25. Martino, V. P., Jiménez, A., \& Ruseckaite, R. A. (2009). Processing and characterization of poly(lactic acid) films plasticized with commercial adipates. Journal of Applied Polymer Science, 112(4), 2010-2018. http://dx.doi.org/10.1002/ app.29784.

26. American Society for Testing and Material-ASTM. (2002). D882-02: Standard test methods for tensile properties of thin plastic sheeting. Philadelphia: ASTM.

27. American Society for Testing and Material-ASTM. (1996). E96-00: Standard test methods for water vapor transmission of materials. Philadelphia: ASTM.

28. Schwach, E., \& Avérous, L. (2004). Starch-based biodegradable blends: morphology and interface properties. Polymer International, 53(12), 2115-2124. http://dx.doi.org/10.1002/ pi. 1636.

29. Müller, C. M. O., Pires, A. T. N., \& Yamashita, F. (2012). Characterization of thermoplastic starch/poly(lactic acid) blends obtained by extrusion and thermopressing. Journal of the Brazilian Chemical Society, 23(3), 426-434. http://dx.doi. org/10.1590/S0103-50532012000300008.

30. Soares, F. C., Yamashita, F., Müller, C. M. O., \& Pires, A. T. N. (2014). Effect of cooling and coating on thermoplastic starch/ poly(lactic acid) blend sheets. Polymer Testing, 33, 34-39. http://dx.doi.org/10.1016/j.polymertesting.2013.11.001.

31. Karagoz, S., \& Ozkoc, G. (2013). Effects of diisocyanate compatibilizer on the properties of citric acid modified thermoplastic starch / poly(lactic acid) blends. Polymer Engineering and Science, 53(10), 2183-2193. http://dx.doi. org/10.1002/pen.23478.

32. Khalil, F., Galland, S., Cottaz, A., Joly, C., \& Degraeve, P. (2014). Polybutylene succinate adipate/starch blends: A morphological study for the design of controlled release films. Carbohydrate Polymers, 108, 271-280. http://dx.doi. org/10.1016/j.carbpol.2014.02.062. PMid:24751274.

33. Xiong, Z., Li, C., Ma, S., Feng, J., Yang, Y., Zhang, R., \& Zhu, J. (2013). The properties of poly(lactic acid)/starch blends with a functionalized plant oil: Tung oil anhydride. Carbohydrate Polymers, 95(1), 77-84. http://dx.doi.org/10.1016/j. carbpol.2013.02.054. PMid:23618242.

34. Teixeira, E. M., Curvelo, A. A. S., Corrêa, A. C., Marconcini, J. M., Glenn, G. M., \& Mattoso, L. H. C. (2012). Properties of thermoplastic starch from cassava bagasse and cassava starch and their blends with poly(lactic acid). Industrial Crops and Products, 37(1), 61-68. http://dx.doi.org/10.1016/j. indcrop.2011.11.036.

35. Alves, V. D., Mali, S., Beléia, A., \& Grossmann, M. V. E. (2007). Effect of glycerol and amylose enrichment on cassava starch film properties. Journal of Food Engineering, 78(3), 941-946. http://dx.doi.org/10.1016/j.jfoodeng.2005.12.007.

36. Mali, S., Sakanaka, L. S., Yamashita, F., \& Grossmann, M. V. E. (2005). Water sorption and mechanical properties of 
cassava starch films and their relation to plasticizing effect. Carbohydrate Polymers, 60(3), 283-289. http://dx.doi. org/10.1016/j.carbpol.2005.01.003.

37. Jamshidian, M., Tehrany, E. A., Cleymand, F., Leconte, S., Falher, T., \& Desobry, S. (2012). Effects of synthetic phenolic antioxidants on physical, structural, mechanical and barrier properties of poly lactic acid film. Carbohydrate Polymers, 87(2), 1763-1773. http://dx.doi.org/10.1016/j.carbpol.2011.09.089.

Received: Feb. 22, 2015

Revised: July 10, 2015 Accepted: Sept. 14, 2015 